\title{
Biology and Architecture: Two Buildings Inspired by the Anatomy of the Visual System
}

\author{
Irem MARO KIRIS \\ Bahcesehir University, Faculty of Architecture and Design-Architecture, Istanbul, Turkey
}

\section{ABSTRACT}

Architectural production has been influenced by a variety of sources. Forms derived from nature, biology and live organisms, had often been utilised in art and architecture. Certain features of the human anatomy had been reflected in design process in various ways, as imitations, abstractions, interpretations of the reality. The correlation of ideal proportions had been investigated throughout centuries. Scholars, art historians starting with Vitruvius from the world of ancient Roman architecture, described the human figure as being the principal source of proportion among the classical orders of architecture. This study aims to investigate two contemporary buildings, namely Kiasma Museum in Helsinki and Eye Museum in Amsterdam, inspired directly from the anatomy of visual system. Moreover the author discussed the relationship of biology and architecture through these two special buildings by viewing the eye and chiasma as metaphors for elements of architecture.

KEYWORDS: Biology-inspired architecture, Chiasma, Eye, Representation, Visual system

\section{DIALECTIC BETWEEN ARCHITECTURE and NATURE}

A rchitecture throughout the course of its history, has become concerned with environmental issues related to the world of nature, and to the historical, sociocultural realm formed by human societies. Architectural design theory, while setting principles and searching for creation of aesthetic and functional harmony, and architectural practice, while shaping the physically built environment, i.e. the urban context, have both received influence, adopted and integrated motifs from the nature.

Art and architecture of all reformative stages of human existence, the antique world, the classical, the Renaissance, the Baroque, and the modern, have developed their approaches for dealing with nature, and representing it in design with regard to varying cultural, territorial, technical conditions. Utilizing nature as a source of inspiration has not only supported architectural creativity but also developed the notions of comprehension, appreciation, experimenting of architecture, and of communicating with the public, the consumer, and the spectator.

\section{BIOLOGY INSPIRED ARCHITECTURE in the CONTEMPORARY WORLD}

The twentieth century has marked the transition from tradition towards modern and set a fertile ground for increased awareness, knowledge and production capacity in the field of architecture. Numerous movements and styles have emerged in industrialized urban centers, among which some with a new understanding of the natural world, and have utilized nature as their main inspiration source and reflected it through use of organic forms, ornamentation, materials and integration of the environment. A unique designer from the turn of the century, Antonio Gaudi, has received inspiration from -often fantasticcreatures of nature and body components such as the skull and bones, as well as plants and floral forms. Leading modernist architects Frank Lloyd Wright and Alvar Aalto have designed buildings with horizontal volumes, curvilinear free forms and natural materials. The Japanese Metabolists of the 1960s and 
their activities ranging from urban planning and architecture to industrial design have influenced whole design world. The metabolists believed that cities and architecture grew and metabolised just as human beings and all living organisms do. They adopted the concept of analogy with living organisms, flexibility, transformability of the physical body, and designed structures, layouts, and urban nets proposing axial and/or unit growth. While the main structure, the spine, survived, its components similar to the organs, extensions, nodes of a body could be replaced as required in time. The structure, space, circulation, installation systems and facades of a building would be considered as the structure, flesh, veins, nervous system and skin of a living organism.

Suggesting a biological, or biomorphic approach to the design of buildings and cities, introducing organic forms and patterns in architectural design seem to have a rich and long history. Organic architecture, metabolism in architecture, and bio-mimicry are all based upon creation of the spatial form/elements that are inspired from the nature, and from the complex orders in nature, biology and/or anatomy of a metabolism.

\section{- ARCHITECTURE and MULTIDISCIPLINARY ISSUES}

The late phase of Modernism or Postmodernism, beginning with 1970s, exhibits a unique architectural language that seems to get more complex as the extent of architecture's integration of multidisciplinary issues and computer technology use increases. Postmodern space and form as well as postmodern culture in general, are characterized mainly by pluralism. Architecture, on one hand, has formed close links with other disciplines such as sociology, philosophy, anthropology, biology, literature etc., and on the other, utilised novel form creation possibilities of computer-aided design technology.

According to Jencks, the architectural form and space of this age had a different agenda than the modernists used to have; complexity, challenge, movement, symbolism, double codes of the age, and the world of postmodernity and globalization to reflect and create the architectural expressions of the period (2). Advances in computerized design and production set new limits for space design and made it possible to realise astonishing forms at a monumental scale. Dynamism, complexity, distortion, disorientation, symbols, metaphors, double codes, narratives and themes rooted in social theory become integral elements of the architecture and architectural expressions of the period. Theoretical texts have been produced acquiring a perception of the building and built environment as representation, expression of philosophical, socio-cultural issues.

Architectural theory of the 1990s places phenomenology as one of the postmodern paradigms of contemporary times. Phenomenology refers to perception on the basis of human consciousness. The phenomenologist approach defines designed space as the place where people could orient and identify themselves through senses, and acknowledges the significance of the human requirements and aspirations.
A perceptive reading of architecture should be practised. Pallasmaa in his book "The Eyes of the Skin: Architecture and the Senses" emphasizes the active role and dominance of the sense of vision in contemporary architecture and calls for a multi-sensory approach in the arts and architecture (5).

Architecture of postmodernity, globalization and the information age, and especially museum architecture, presents impressive and iconic examples. Museum architecture has always been an important field of experimentation, a medium displaying a variety in thematic conceptualisation of space. In this text, among museum buildings that trace the route of biology/anatomy inspired architecture with their forms and images, two that are representative of the world of visual arts, will be the focus; Kiasma by Steven Holl and the Eye by Delugan Meissl AA. These contemporary museum buildings, designed by international practice and constructed in northern European capitals, Helsinki and Amsterdam, exhibit common features. Their architecture in terms of design approach, physical context, layout, creation of form and image, and spatial patterns, hereby, shall be discussed.

\section{KIASMA of HELSINKI, MUSEUM of CONTEMPORARY ART (Figures 1, 2, 3)}

Kiasma is a contemporary art museum located on Mannerheimintie in Helsinki, Finland, constructed between 1996 and 1998. The project was the winner of a design competition held in 1993. The title 'Kiasma' was chosen by its designer Steven Holl, as the competition entry code of the project that is also related with the form, scheme and the overall concept 'intersection'. The name Kiasma in Finnish language, comes from 'chiasma' that is originally derived from 'chi', a letter of Greek alphabet, meaning 'crossing, exchange'. It is known as a medical term mostly used in anatomy and genetics; the anatomical crossing of the optic nerves at the base of the brain. The architecture of the museum building, composing of intertwined linear volumes, reflects a similar pattern in large scale.

Holl has designed a number of other museums around the world, including museums of natural history in Los Angeles and Copenhagen, an art museum in Nanjing, China, and the Knut Hamsun Center in Hamaroy, Norway. He is known for his architectural solutions in which he pursues the phenomenological approach. Holl uses watercolor sketches to visualize the formation of the conceptual design, the phenomenal, experimental potential of the concept. Interplay of masses, light and dark, void and solid, volumes that are seamlessly integrated with the context, are known to be dominant features of his architecture, most of which are observed in Kiasma.

Kiasma fits into a sloping triangular site at a strategic location with a short distance to important urban axes, in relation with other architectural attractions; to the east reaching a busy urban node and the station building by Eliel Saarinen, to the north widens to curve around two axes; one reaching Alvar Aalto's cultural center, Finlandia Hall, and the second connecting to Töölö Bay. On the west, a major route connects the building to city center, Finland's Parliament Building and the National Museum. There stands the statue of Mannerheim 


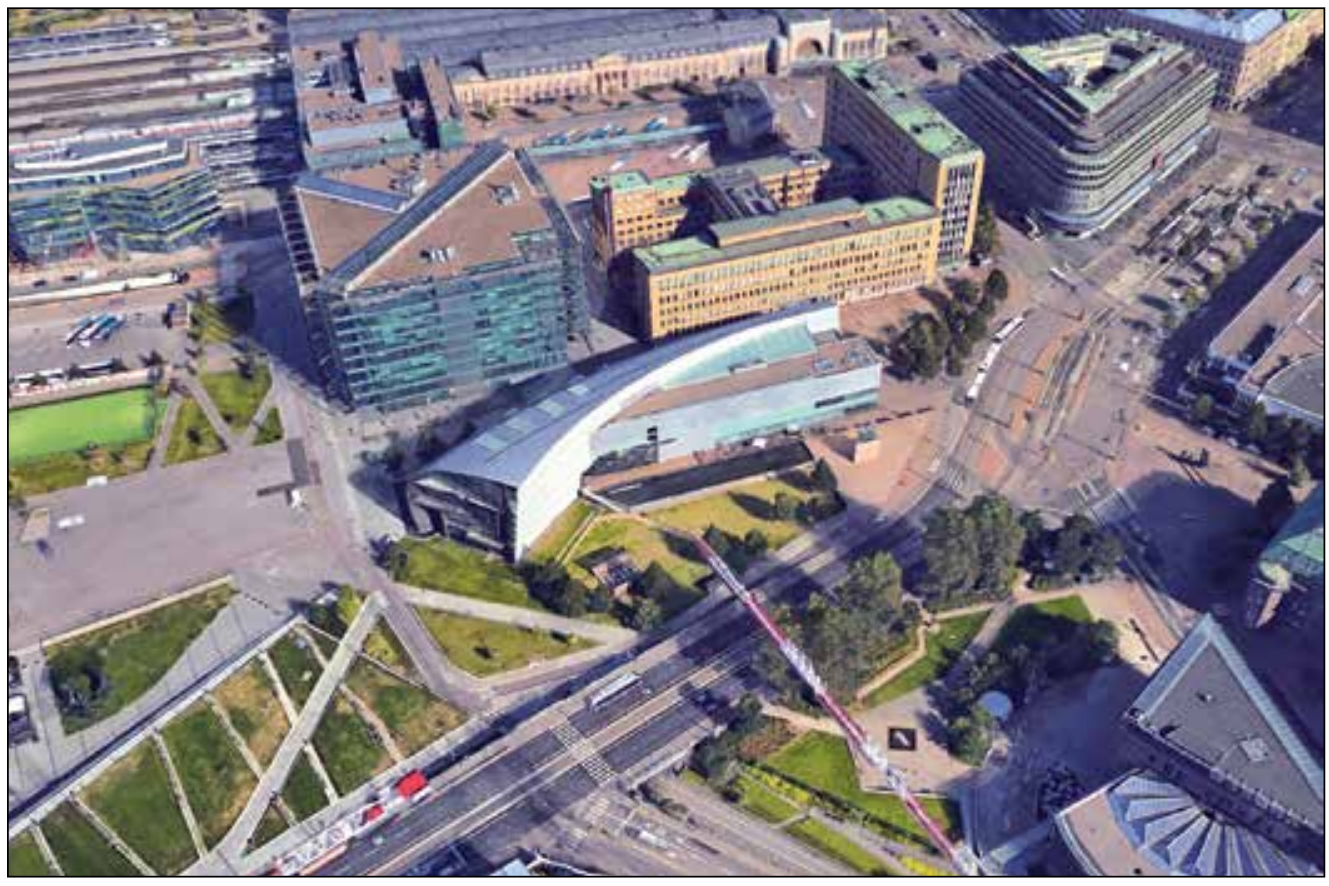

Figure 1: Aerial view of Kiasma Museum Helsinki.

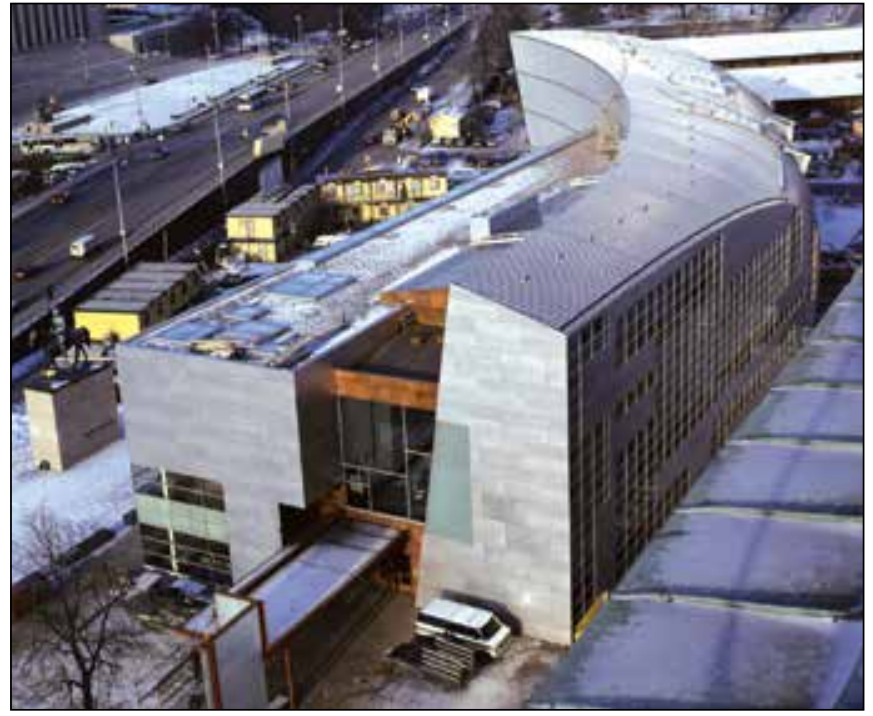

Figure 2: Entrance facade of Kiasma Museum Helsinki.

at the center of the plaza in west direction. Within the urban context of significant architectural, cultural references, Kiasma forms strong connections with its surroundings, both in means of volume and space and as a culture building, its layout embracing Helsinki's architectural legacy (6). The urban/cultural axes, building mass and landscape are intertwined.

Environmental resources, natural as well as urban, have been integrated into the architecture of Kiasma. For instance, water running through the building, reaching an open air pool built on the western facade, was provided from the Töölö Bay. Sound of water, reflections, play of light, volumes and spaces in dialogue are experienced as features related to sensuality, they accompany the visitors during their stay in the building.

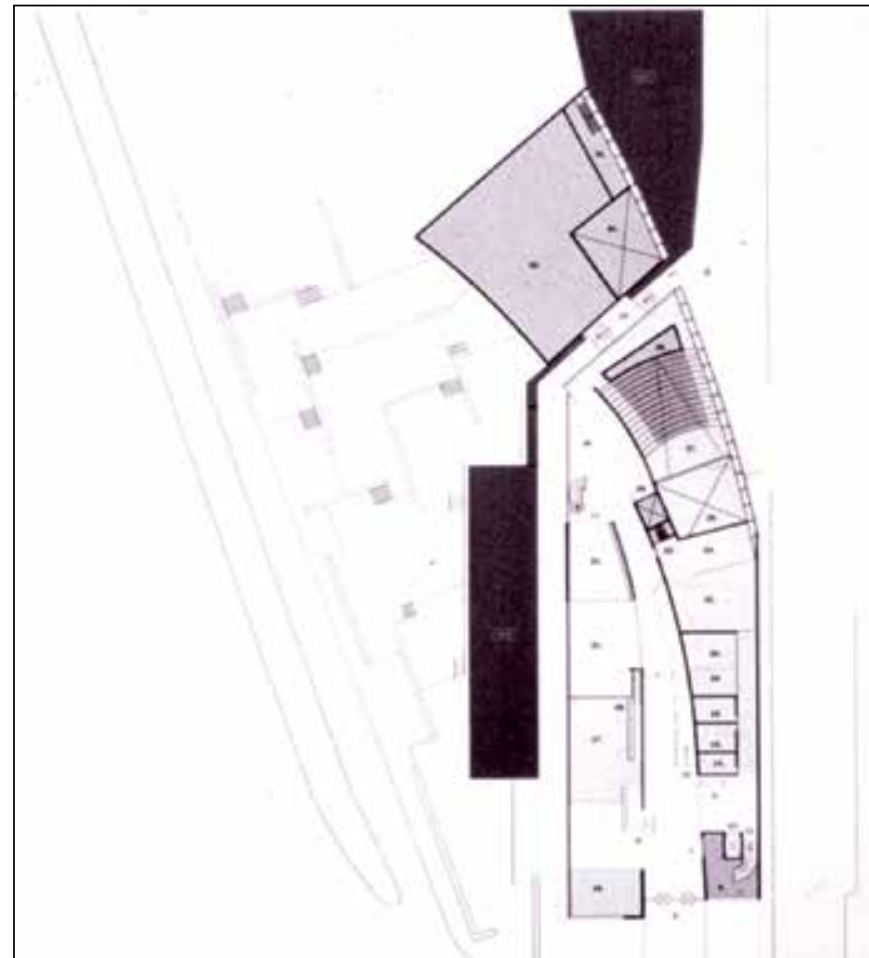

Figure 3: Plan layout of Kiasma Museum Helsinki.

The lay-out of Kiasma, comprises three parts "a bar of water and two bars of building" (3). On the south, the entry opening in between the two horizontal volumes exist as if it was a grove, a fissure - dividing an organ into lobes- and it is marked by an extending canopy, the starting point of a promenade through the building. This overhanging plane functions as a solar panel, and together with the angled skylights, acts as a 
system for collecting, directing and diffusing daylight into the spaces.

Kiasma's sculptural volumes, the wing with a curved outer wall and a rounded roof, and the wing with the flat roof and straight wall meet and create a crossing, resembling the structure of the optic nerve, the inspiration source for design. "The optic nerve which carries sensory nerve impulses from the cells of the retina to the visual centers of the brain, begins at the optic disc located at the back of the eye. As the nerve emerges from the back of the eye, it passes through the posterior orbit and the bony optic canal to emerge intracranially on the underside of the front of the brain. At this point the optic nerve from each eye, comes together and forms an X-shaped structure called the optic chiasm. Forms the arrangement that is essential for producing binocular vision." (1).

Kiasma's intertwined volumes, crossing and the curving wing create continuously changing perspectives and sequential spaces of various form and sizes; galleries, artists workshops, cafe, shop, theatre. Flexibility is provided in the interior spaces; museum space can function as a whole or as a series of galleries, as an art forum or adapt to different cultural events, performances, and exhibitions. The cafeteria facing both the entrance hall and the garden, can be transformed into a meeting room.

\section{च EYE FILM MUSEUM of AMSTERDAM (Figures 4,5,6)}

The Eye Museum of Amsterdam has been one of the world's major film museums since its foundation in 1946. Its new building that was opened to public in 2012, had adopted the form of an eye literally, and the volume and the facade with its composition of solid and transparent surfaces all together, give the impression of an eye in monumental scale to the spectator. It has been built as a part of the urban development program for Overhoeks region that carries the potential of growing into a cultural district. Today, together with the A'DAM Tower and the Tolhuistuin, the Eye provides a landmark building situated at a strategic location on the north bank of the river IJ overlooking the city from a distance. The Eye Museum urges the visitors, both citizens and tourists, to cross the river and therefore acts as a bridge between the historical centre and northern part of the city (4).

The designers, Vienna based Delugan Meissl Associated Architects (DMAA), known for their designs for Porsche Museum in Stuttgart and Tyrol Festival Hall in Erl, are fond of creating expressive, dynamic volumes, sculptural forms that relate to the context similar to the way living organisms relate to their ecosystems. Similar features can be observed in the architecture of the Eye. The dynamic, impressive building form of the Eye is perceived as a whole, and it is meaningful as a whole, since it is an interpretation of the human eye. However, the building's cantilevered wings at both ends and the central part can be read as three parts of the steel structure that are in balance, design-wise and structurally. Flexibility, flowing sequence of spaces, reflections, interplay of light and dark, integration of open and closed spaces, landscape and the building, play significant roles in the design of the Eye. DMAA's design approach was based on expressing the experience of film through the experience of architecture; through changing, sequential spaces, scenes, light, depending on the route one takes, and the time of day, when visiting the museum. The building and organisation of spaces, offer constantly changing views from different angles, born out of the form, light, reflections, similar to the art of the moving images, cinema.

As a film and culture center for the visual arts, the building houses various functions spread in flexible spaces of four different levels: A secondary entry, permanent exhibition area and a cinema hall at its lowest level; lobby, museum shop, central gallery 'Arena' with surrounding seats forming an amphitheater, cafeteria, terrace and two cinema halls at the main entrance level; screening and exhibition space at the upper level, and another cinema hall at its top level. Two elevators besides the staircases, one connecting two low levels, the other leading to the top floor, provide vertical circulation of the Eye. Vast open spaces where almost all planar elements, walls, floors and ceilings are at different angles to one another forming complicated points of contact, white stucco finishes on ceiling and solid walls, timber flooring that covers the entire ground area, the bar with its central gallery space and the stairs, and glazed facades open to view of the River IJ and the city, are observed as distinctive elements of interior space. The exhibition area and the Arena seem to be designed as a whole continuous, harmonious space. Interior space and the terrace, as well as the open entrance plaza, offer vista points for changing views of the river and the city. The museum building spatially contributes to the IJ promenade.

\section{POWER of the IMAGE - of the EYE - as REPRESENTATION}

Kiasma and the Eye buildings both act as busy urban nodes that are strongly connected to the physical and cultural context they are located in, providing appropriate medium for public interaction. With their dynamic, experimental forms, both have become architectural highlights, popular icons of their urban environment, and attributes to the cityscape. The appeal and popularity they achieved, owe to their unusual forms inspired by live organism imagery. In both designs, the designers' conceptual approach had employed the visual system for representation of exploring the world of art. They seem to have used a universal architectural language to communicate with the public, the visitor, the spectator. The anatomy of the eye, the essential mechanism to see, observe, perceive the world, life and art, had inspired the architects for creating the innovative designs of these museum buildings. In Kiasma, the structure of the optic nerve, in the Eye, the eye form had been imitated. Result is an expressive, sculptural architecture celebrating the power of the image on one hand, on the other an architecture that closely relates to the environment, based on the experience of space, perception and senses of the visitor/spectator; an architecture that integrates the conceptualisation of live organism imagery derived from nature, through spatial, formal sequences, motifs such as interplay of volumes, light and dark, solid and void, interior and exterior, roles given to light, water, reflections in design. 

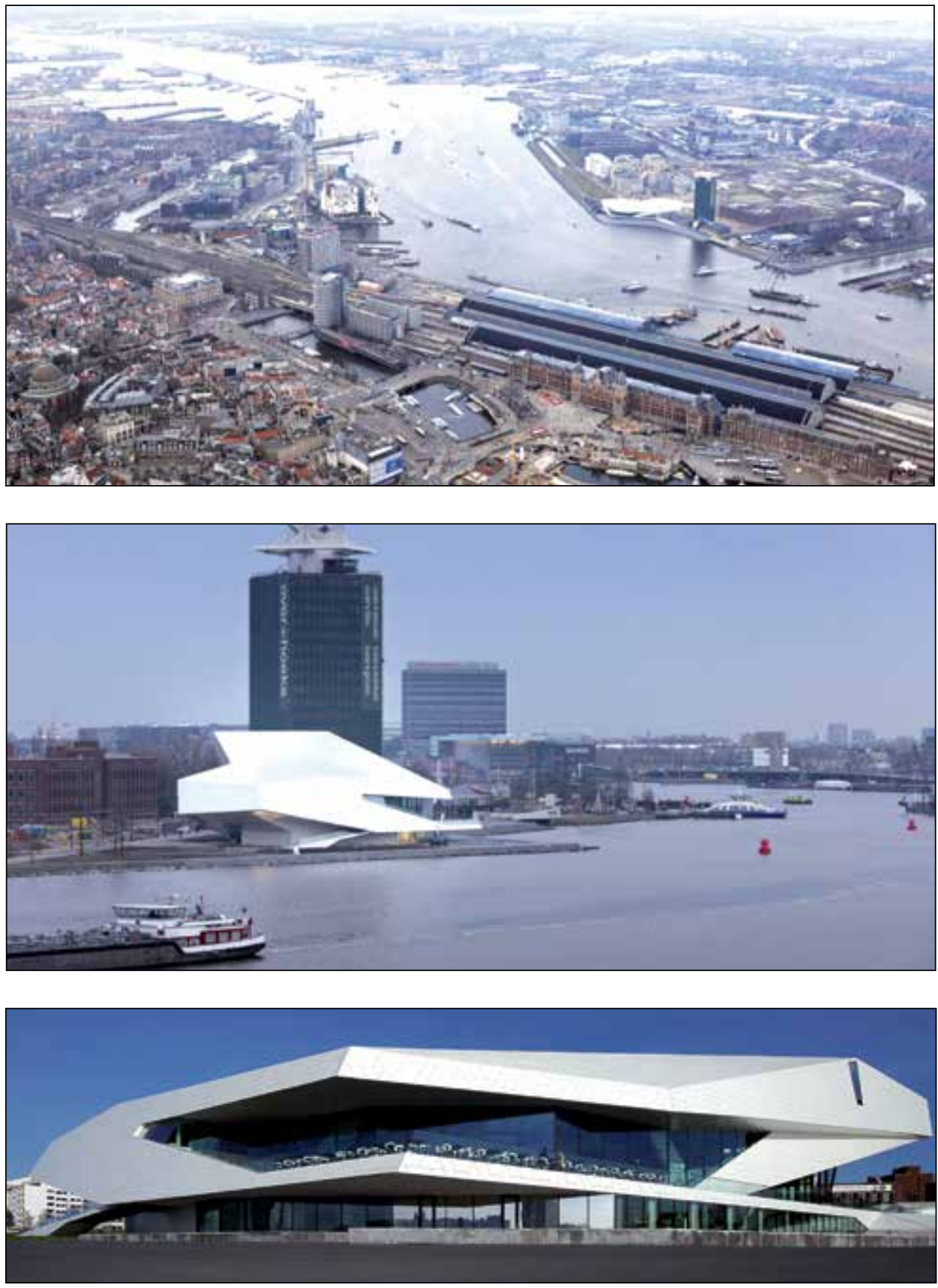

Figure 4: Eye Museum Amsterdam has been built as a part of the Urban Development Program on the north bank of the River IJ.
Figure 5: Eye Museum Amsterdam picture from a lateral view resembling an open eye figure with upper and lower lids.
Figure 6: Front facade of the Eye Museum Amsterdam facing the river, resembling the form of a narrowed eye.
Human figure anatomy and senses, acting as a spectator, as an explorer of art and space, acting as a model for design, in one way or another, seem to get involved in this architecture.

Perceived as landmarks, urban symbols today, these museum buildings, through an architecture of dynamism, energy, sensuality, and bio-mimicry, are representative of the spirit of the age, global cultures, art and architecture.

\section{- REFERENCES}

1. Albert DM, Gamm DM: Optic nerve anatomy. Available at https://www.britannica.com/science/optic-nerve. Accessed April 4th 2018
2. Jencks C: The language of post-modern architecture and the complexity paradigm. In: Jencks C (ed), The Post-Modern Reader, John Wiley \& Sons, 2011:162-177.

3. Lecuyer A: 1998 August: Art Museum, Steven Holl Architects (Helsinki, Finland). The Architectural Review, E-Article (21 Sept. 2011), Accessed April 4th 2018,

4. Lier VB: Eye film museum official book. Eye at a Glance, @2016 EYE, Amsterdameyefilm.nl.

5. Pallasmaa J: The thinking hand: Existential and embodied wisdom in architecture, John Wiley \& Sons, 2009:21.

6. Stein K: Breaking the mold: Kiasma Museum, Helsinki. Architectural Record, 1998 